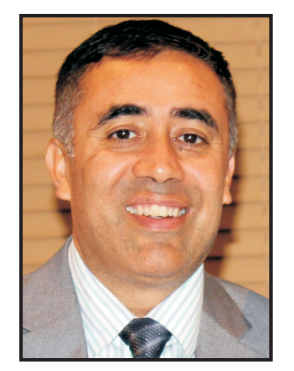

\title{
MESSAGE FROM CHIEF EDITOR
}

Ever since the dawn of civilization, humans have been inclined towards knowledge and the quest to seek the truths that govern the way our world, our societies and our very own bodies organize, coordinate and work. This journey that we have embarked on this ever changing world wouldn't be possible without research, its findings and its proper documentation. Medicine and medical education especially wouldn't be anywhere near as advanced as it is now if it weren't for the works of great thinkers and researchers of the past and present. I believe it is now up to us, the medical educators, practitioners and students to continue this expansion of knowledge and seek new and innovative ways to understand medicine through research and documentation.

The publishing of BJHS will go down as a historical moment for Birat Medical College, as it is the first step towards a greater goal for medical education. The encouragement to learn and partake in research can only further fuel the students towards becoming better medical practitioners. Research makes it possible to provide holistic care that better serves the environment of today. The research that occurs in a particular community is directly proportional to the quality of medical care that it will receive. This is due to the fact that research provides us the demographics related to the needs of the target community. In this way, the establishment of BJHS will serve as a beacon to all medical professionals to conduct research and ask questions.

BJHS is a tri-annual, peer reviewed and indexed journal which strives towards publishing original and authentic articles encompassing medical, nursing, community health and public health. The Journal will contain original articles, review articles, case reports, case series and editorials. The unbiased and un-opinionated peer review system should effectively filter the authenticity and importance of articles in today's medical domain. In my leadership and with the collective efforts of the entire editorial board, we hope to successfully not only encourage research, but establish a global platform on which the findings can be displayed.

I am sure it will take time for this journal to really make its mark on the health sector, but all good things come to those who wait and those who persevere through adversity. At one point in time this Journal was barely an Idea, and before long it has now materialized into a working unit. Our chairman Dr. Gyanendra Man Singh Karki was extremely enthusiastic about the publishing of Birat Journal of Health Sciences (BJHS), also this wouldn't be possible without the support of our Principal Prof. Govinda Prasad Sharma. I would also like to acknowledge the backing of Mr. Denis Karki, the Vice Chairman of this college for his relentless encouragement and utmost support in this endeavor. But of course, the most important roles belong to the authors and editors of today and tomorrow to keep this journal growing and flourishing, for there is no journal without you.

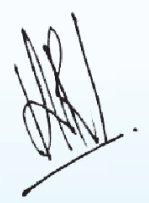

\section{Dr. Hem Sagar Rimal}

Editor in Chief

Birat Journal of Health Sciences 